\title{
Nanoparticle Production
}

National Cancer Institute

\section{Source}

National Cancer Institute. Nanoparticle Production. NCI Thesaurus. Code C113045.

The production of small, stable particles whose size is measured in nanometers. 